\title{
POLITIZACIONES GENERACIONALES Y PROCESOS DE TERRITORIALIZACIÓN EN LAS PERIFERIAS URBANAS: LA EXPERIENCIA DEL SUR DEL GRAN BUENOS AIRES ENTRE LOS AÑOS OCHENTAS Y LA ACTUALIDAD ${ }^{1}$
}

\author{
PABLO VOMMARO ${ }^{2}$ \\ ARLEY GIOVANNY DAZA ${ }^{3}$
}

\begin{abstract}
RESUMEN
El artículo se propone analizar con perspectiva diacrónica las dinámicas espaciales de la participación juvenil como ámbito en el que se despliegan constantes disputas territoriales y se producen prácticas políticas, tanto portadoras de tradiciones y continuidades, como emergentes y disruptivas. Partimos de la hipótesis según la cual los modos participación y militancia y los rasgos que se producen a partir de las potencialidades singulares de las dinámicas juveniles, instituyen configuraciones generacionales de la política territorialmente situadas. En ellas conviven formas de construcción social del territorio que expresan procesos que pueden ser explicados socio-históricamente. En este sentido, el territorio será abordado como el lugar en el que convergen múltiples experiencias al igual que diversas capas espaciales y temporales superpuestas y en donde se despliegan formas de práctica y militancia políticas que nos invitan a interpretaciones no lineales, subvirtiendo explicaciones unidimensionales y buscando en la trama situada del proceso histórico los elementos que contribuyan a comprender sus rasgos.
\end{abstract}

PALABRAS ClAVE: MILITANCIA JUVENIL, POLITIZACIÓN, TERRITORIO, GENERACIONES.

${ }^{1}$ Este artículo hace parte del trabajo colectivo desarrollado en el marco del Grupo de Estudios de Políticas y Juventudes (GEPoJu), que funciona en el Instituto de Investigaciones Gino Germani de la Facultad de Ciencias Sociales de la Universidad de Buenos Aires y del cual los autores son integrantes.

${ }^{2}$ Pos doctor en Ciencias Sociales, Niñez y Juventud. Doctor en Ciencias Sociales y Profesor de Historia de la Universidad de Buenos Aires. Investigador del CONICET y del Instituto de Investigaciones Gino Germani (UBA). Co-coordina el Grupo de Estudios de Políticas y Juventudes (GEPoJu- IIGG) e integra Grupo de Trabajo de CLACSO “Juventudes e infancias: políticas, culturas e instituciones sociales". Es docente en la Facultad de Filosofía y Letras de la UBA en grado y posgrado. Correo electrónico: pvommaro@gmail.com

${ }^{3}$ Magíster en Ciencias Sociales con orientación en Educación. Licenciado en Comunicación Social y Periodismo. Miembro del Grupo de Estudios de Políticas y Juventudes (GEPoJu -IIGG) e integrante del Grupo de Trabajo CLACSO "Pueblos originarios en lucha por las autonomías movimientos y políticas en América Latina”. Correo electrónico: samporf@gmail.com 


\title{
POLITIZAÇÕES GERACIONAIS E PROCESSOS DE
}

\author{
TERRITORIALIZAÇÃO NAS PERIFERIAS URBANAS: A \\ EXPERIÊNCIA DO SUL DO GRANDE BUENOS AIRES ENTRE \\ OS ANOS OITENTA E A ATUALIDADE
}

\begin{abstract}
RESUMO
Este artigo visa analisar com perspectiva diacrónica as dinâmicas espaciais da participação juvenil como âmbito no qual acontecem constantes disputas territoriais e são produzidas práticas políticas, tanto portadoras de tradições e continuidades, quanto emergentes e disruptivas. Começamos da hipótese segundo a qual os modos participação e militância e os traços que são produzidos a partir das potencialidades singulares das dinâmicas juvenis, instituem configurações geracionais da política territorialmente situadas. Nelas convivem formas de construção social do território que exprimem processos que podem ser explicados sócio - historicamente. Neste sentido, o território será abordado como o lugar onde convergem múltiplas experiências da mesma forma que diversas camadas espaciais e temporais superpostas e onde aparecem formas de prática e militância política que nos convidam a interpretações não lineais, subvertendo explicações unidimensionais e procurando na trama situada do processo histórico os elementos que contribuam para compreender seus traços.
\end{abstract}

PALAVRAS- CHAVE: MILITÂNCIA JUVENIL, POLITIZAÇÃO, TERRITÓRIO, GERAÇÕES.

\section{GENERATIONAL POLITICIZATIONS AND}

\section{TERRITORIALIZATION PROCESSES IN OUTSKIRTS: THE}

\section{EXPERIENCE IN THE SOUTH OF GRAN BUENOS AIRES}

\author{
BETWEEN THE 80S AND NOWADAYS
}

\begin{abstract}
The article analyzes diachronically the spatial dynamics of youth participation as the ground for consecutive territorial struggles and political practices both traditional and continuous, emerging and disruptive, starting from our hypothesis of how modes of participation and affiliation, and their features resulting from particular potentialities of youth dynamics, establish co-existing socio-historically explainable, generationally defining processes of territorial politics. The territory will be tackled, then, as the place where multiple experiences, as well as spatial and temporal superposed layers, converge, also displaying diverse ways of political affiliation and practice, encouraging non-lineal interpretations, subverting one-dimensional explanations and searching for characteristic elements within the path of the historical process.

KEYWORDS: YOUTH AFFILIATION, POLITICIZATION, TERRITORY, GENERATIONS.
\end{abstract}




\section{Presentación}

Como parte de las transformaciones de mediana duración que experimentó el capitalismo durante la segunda mitad del siglo XX, podemos identificar que la dimensión territorial ha tomado un creciente protagonismo en los modos de ser y en las dinámicas sociales. Esto llevó a que algunos autores coincidan en que desde el siglo XIX las sociedades occidentales comenzaron a experimentar un cambio sustancial yendo desde el reinado del plano temporal hacia una dimensión espacial-territorial en la que el mundo se experimenta menos como una gran vida que se despliega en extensidades a través del tiempo, que como una red de intensidades espaciales que articula puntos y se entrama (Foucault, 1984; Soja, 2011). Así, el territorio toma relevancia en tanto elemento material que expresa construcciones simbólicas con fuerte incidencia social; puede ser construido, reproducido y modificado en una relación de doble vía que deviene en la producción de lo otro mediado por la espacialidad, sus formas y potencialidades. En este sentido también es productor, reproductor y agente modificador de diversas configuraciones de la política entre las que destacamos la generacional, que abordaremos en este artículo. Esta transformación desplegada con fuerza en las últimas décadas focalizó los análisis en un elemento que, hasta entonces, no había sido tomado en cuenta con la suficiente relevancia: la espacialización de la política y su singularidad práctica tanto en el espacio vivido, inmediato, tangible, como también en el espacio social más abarcativo y simbólico.

En este artículo nos proponemos analizar en clave juvenil y desde una perspectiva diacrónica las dinámicas espaciales de la participación política que podemos considerar no institucionales en barrios de la periferia sur de la Ciudad de Buenos Aires. Entendemos esta producción de la participación con perspectiva generacional como un proceso en el que se despliegan disputas territoriales, prácticas políticas que continúan y otras que emergen, a la vez que 
múltiples construcciones y tensiones político comunitarias de dimensión local y más general.

Consideramos que los procesos de politización de la vida social abordados desde la perspectiva expuesta generan una transformación en las relaciones entre la política y el espacio en el cual ésta es producida. Así, el espacio socialmente producido, concebido como un entramado de relaciones político-sociales dinámicas, deviene territorio; configura un proceso ambivalente de territorialización de la política y de politización del territorio (Vommaro, 2015).

Sostenemos entonces que durante las últimas décadas en la Argentina como parte de una dinámica más general- se produjo un proceso de politización del espacio que territorializó las prácticas políticas. Esto puede ser interpretado desde las configuraciones generacionales que potenciaron su despliegue, a la vez que desde una perspectiva diacrónica que contribuye a la comprensión integral del proceso. Si bien estos rasgos comenzaron a gestarse a fines de los años sesenta, es en los tempranos ochenta cuando se consolidan y emergen tramando la política territorialmente situada. En este sentido, las formas políticas producidas por las juventudes en décadas posteriores estarían signadas por pervivencias que, actualizadas y reconfiguradas, contienen muchos de las principales características de la politización espacial del período en el que comenzamos nuestro análisis.

De esta manera, en este trabajo realizaremos un acercamiento a las formas territoriales de producir política en clave generacional a partir de tres experiencias de participación y trayectorias territoriales de militancia juvenil desplegadas en las últimas décadas en la zona sur del Gran Buenos Aires (Argentina), específicamente en el partido de Quilmes, ubicado en el sudeste del conurbano bonaerense, a 17 kilómetros de la capital argentina.

Los habitantes de Quilmes poseen algunos elementos que subrayan una singularidad significativa respecto a otras zonas del mismo cordón urbano en 

periferias urbanas

cuanto a densidad organizativa, desarrollo productivo y conflictividad política sostenida en el tiempo. Según Fidel, Di Tomaso y Farías (2008) un 75,6\% de la población de este distrito tenía en el año 2008 “algún grado de vinculación o participación” en organizaciones y/o instituciones barriales. Además, dicen los autores, las relaciones sociales solidarias y de confianza entre los habitantes de la zona son particularmente fuertes y persistentes. Los vecinos de Quilmes presentan una “alta participación” sostenida en las redes de organización territoriales; las "relaciones de confianza y el alto sentido de asimilación territorial" dan lugar a "relaciones solidarias" entre ellos, sobre todo en los barrios más pobres del municipio. Este “sentido de pertenencia territorial” se potencia aún más con la valoración que detectan los autores citados de "las organizaciones formales e informales” que existen en los barrios destacando los “fuertes lazos de amistad" entre los vecinos, lo que configura "una arquitectura social y de amistad" reforzada por los "lazos de solidaridad y ayuda mutua”, especialmente sólidos y extendidos en la zona (Fidel, Di Tomaso y Farías, 2008: 132).

Asumiendo estos puntos de partida, en este artículo pondremos en discusión tres nociones transversales a las décadas abordadas. Estas son: la autonomía configurada en el proceso de institución del territorio, la producción en el territorio y la diversidad que emerge desde el territorio. Consideramos estas dimensiones como constitutivas de la acción política con capacidad de reconfigurarse al ser producidas por las lógicas surgidas desde las comunidades y su multiespacialidad.

Así, entre fines de los años setentas y comienzos de la década del ochenta, durante la dictadura militar, las experiencias organizativas profundizaron su nivel de autonomía, constituyéndose ya no en oposición, sino como alternativa, en paralelo o en fuga respecto al Estado. En los años noventas las organizaciones ahondaron sus propuestas productivas, ensayando lógicas distintas de organizar la producción y el trabajo e instituyendo espacios 
de autogestión, auto-organización y autovaloración de la fuerza de trabajo. Por último, luego de la denominada crisis de 2001 se desplegaron procesos espaciales que expresaron la visibilización de prácticas colectivas emergentes y diversas multiplicando los sentidos de la dinámica territorial.

Para la década del ochenta tomaremos experiencias de jóvenes militantes que condensan distintas formas de participación y práctica política como parte del proceso de tomas de tierras y construcción de asentamientos, y del accionar de las Comunidades Eclesiales de Base -CEBs- en la zona de Quilmes. Abordaremos formas militantes juveniles que nos permitirán entender cómo las experiencias de participación política se entrelazan alimentando entramados organizativos anclados a nivel territorial que dinamizan las configuraciones políticas con perspectiva generacional. La construcción de formas políticas tendientes a la autonomía y la producción de territorios en tanto ocupación y politización del espacio guiarán el análisis.

En segundo lugar, trabajaremos los años noventa a partir de las formas de participación producidas por los jóvenes organizados en los denominados Movimientos de Trabajadores Desocupados -MTD-, específicamente con el MTD de Solano, enfocados en sus espacios de producción y en las prácticas cotidianas. En este sentido, estudiaremos los denominados talleres productivos de esta organización y las dinámicas que se producían en las diversas acciones de ocupación del espacio público. La producción situada en el territorio -que en la época se resumió en la frase "la nueva fábrica es el barrio”-4, orientará el estudio de este momento.

Por último, para el período post 2001 analizaremos la experiencia de un agrupamiento juvenil indígena cuyas formas de participación y militancia

\footnotetext{
${ }^{4}$ Esta frase fue popularizada por la Central de Trabajadores Argentinos (CTA) en los años noventas como una forma de dar cuenta de los cambios sociales y económicos de esa década y el creciente trabajo territorial de esa organización que se volcó al barrio como espacio productivo que había cobrado relevancia política.
} 

periferias urbanas

comunitarias aportan elementos singulares, alteridades y estrategias diversificadas de expresión y visibilización comunitarias desde la diferencia. Se trata del colectivo juvenil de la comunidad indígena Toba-Qom Yapé en Bernal Este, también en el Partido de Quilmes. Aquí nos proponemos identificar el proceso por el cual la memoria se convierte en una herramienta política y territorial al igual que los modos en que memoria, etnicidad, práctica política y espacialidad se articulan para configurar las acciones colectivas de las juventudes indígenas en contexto urbano.

Estudiaremos las tres experiencias a partir de una metodología de carácter cualitativo basada en entrevistas, observaciones y análisis de documentos producidos por los espacios políticos seleccionados. Utilizaremos tanto entrevistas propias -en profundidad, en algunos casos de tipo historia de vida- que fueron realizadas a partir de aproximaciones etnográficas al campo, como así también otras tomadas de estudios acerca de las experiencias analizadas. En algunos casos las personas entrevistadas son citadas con su nombre completo real -cuando consideramos que su identificación contribuye a la comprensión del momento y recibimos su autorización para hacerlo-, mientras que en otros casos utilizamos nombres ficticios con el objeto de resguardar la identidad de la persona informante.

\section{LOS AÑOS OCHENTA: ENTRE LA PRODUCCIÓN DE TERRITORIO Y LA POLÍTICA DE LA AUTONOMÍA}

Las juventudes comenzaron a movilizarse años antes de la recuperación de la democracia en la Argentina en diciembre de 1983, a partir del malestar creciente contra el gobierno dictatorial y los efectos de las políticas represivas desplegadas especialmente sobre los y las jóvenes, más aun si eran trabajadores, 
estudiantes o militantes. ${ }^{5}$ Esta movilización fue promovida y accionada, centralmente, desde formas de participación locales, moleculares, que buscaban ensanchar los intersticios existentes en el régimen militar.

Al respecto, existen estudios que muestran cómo muchos jóvenes trabajadores habían protagonizado las principales formas de resistencia molecular a la dictadura en los lugares de trabajo (Pozzi, 1988; Falcón, 1996 y Gresores, 2002); las huelgas convocadas por la denominada CGT Brasil -ex “Comisión de los 25”- a partir de 1979, en las iniciativas impulsadas por la Iglesia Católica, como la llamada Marcha "Paz, Pan y Trabajo” en noviembre de 1981, y en las Comunidades Eclesiales de Base que impulsaron las tomas de tierras y los asentamientos de 1981 en la zona sur del Gran Buenos Aires (Vommaro, 2006 y 2010; Fara, 1989). En esta última experiencia nos centramos en este apartado.

En relación con la militancia juvenil estudiantil, los colectivos universitarios comenzaron a reagruparse en el invierno de 1982 en el marco de las comisiones en solidaridad con la Guerra de Malvinas y, poco después, en el marco de las “comisiones reorganizadoras” de los centros de estudiantes (Blanco et. al., 2014). La regularización de la Federación Universitaria Argentina (FUA) y Federación Universitaria Buenos Aires (FUBA) llegarían hacia fines de 1983, con una participación enmarcada en filiaciones político partidarias (Toer, 1988). Los centros de estudiantes secundarios, también comenzaron a expresarse muy incipientemente hacia fines de 1982 y en 1983, enmarcados asimismo en adscripciones partidarias. En este sentido, es posible observar que el activismo juvenil comenzó a manifestarse en el espacio público en los años previos a 1983, dando forma a las modalidades de participación caracterizadas fundamentalmente por el entusiasmo por la recuperación de la

${ }^{5}$ Esta dimensión generacional del genocidio y la represión militar se apoya en las cifras producidas tanto por la CONADEP como por el Espacio para la Memoria que permiten afirmar que más del $77 \%$ de las personas desaparecidas por la dictadura entre 1976 y 1983 eran menores de 25 años. 
democracia y las maneras de militancia vinculadas a las instituciones republicanas.

En este marco, los sectores sociales más golpeados por las políticas sociales, económicas y espaciales impuestas por la dictadura ${ }^{6}$ vieron en los inicios del periodo alfonsinista una posibilidad de mejorar sus condiciones de vida. Esto se expresó en una redistribución espacial hacia las periferias de las áreas metropolitanas, tanto desde zonas céntricas de las ciudades de las cuales fueron expulsados, como desde las provincias argentinas, sobre todo las del Noreste, Noroeste y Litoral lo que derivó en un alto índice migratorio interno campo/ciudad y centro/periferia al interior del espacio urbano- durante la década del ochenta. Asimismo, se produjo un crecimiento de los niveles de desocupación y pobreza como consecuencia de las políticas aplicadas por el gobierno dictatorial hecho que generó un engrosamiento de los cordones periféricos y sectores periurbanos de las grandes ciudades.

Como parte de este proceso de desplazamiento y segregación espacial a la vez que cristalización de la emergencia de la producción política del territorio, entre los meses de agosto y noviembre de 1981 se produjeron tomas de tierras en los partidos de Quilmes y Almirante Brown que dieron lugar a la organización de seis asentamientos: La Paz, Santa Rosa, Santa Lucía, El Tala, San Martín y Monte de los Curas -actual Barrio 2 de abril. De este proceso, que significó la ocupación de unas doscientas once hectáreas, participaron alrededor de cuatro mil seiscientas familias, es decir unas veinte mil personas

${ }^{6}$ Erradicación compulsiva de villas, indexación de alquileres, nuevo código de planeamiento urbano tanto en la Capital Federal como en la Provincia de Buenos Aires, construcción de autopistas y expropiaciones que dejan desprotegidos a los inquilinos, entre otras medidas que profundizaron el aumento de la pobreza por aquellos años (Vommaro, 2010). 
aproximadamente, en su gran mayoría menores de 35 años. ${ }^{7}$

Si bien para algunos autores los procesos organizativos que confluyeron en estas tomas y los asentamientos de comienzos de la década del ochenta poseen una impronta sindical y fabril en tanto pervivencia de la década del setenta, desde nuestra lectura y a manera de hipótesis, dichos procesos se potenciaron en el acontecimiento mismo de las tomas y se fueron fortaleciendo en las dinámicas comunitarias que allí se expresaron y desplegaron. En este sentido, resultaron claves las experiencias agrarias de los migrantes internos al igual que el aporte de militantes que antes de 1976 participaban en sindicatos y partidos políticos e incluso en organizaciones armadas como Montoneros. Sin embargo, resultó especialmente relevante el acompañamiento de las Comunidades Eclesiales de Base (CEBs), las que impulsaron el proceso. Estas surgieron en América Latina como expresión de los cambios que se produjeron en la Iglesia católica luego de la Segunda Guerra Mundial. Según Magne, las Comunidades eran

pequeños grupos religiosos casi siempre creados por representantes pastorales -obispos, sacerdotes, monjas-, quienes se reunían en iglesias, casas o centros comunitarios dedicando la mayor parte del tiempo al estudio y lectura de la Biblia. En contraste con la parroquia tradicional, acentuaban la participación la igualdad, el liderazgo seglar, la toma de conciencia y la militancia socio-política. (Magne, 2004: 40)

Así, las CEBs, en tanto espacios vinculados con la Iglesia católica con una impronta barrial importante, constituyeron una forma alternativa de vínculo entre la Iglesia y los conflictos sociales que comenzó a consolidarse décadas atrás. Tuvieron la particularidad de permitir un rol protagónico de mujeres y jóvenes ya fuese mediante la aparición de sacerdotes comprometidos con la

${ }^{7}$ Construcción propia a partir de los artículos periodísticos relevados y de los textos de Izaguirre y Aristizábal (1988), Guzmán (1997) y Cuenya et al. (1984), Fara (1989) y Vommaro (2010). 
práctica social y política o de grupos de jóvenes laicos organizados, además de atribuir una especial importancia a lo territorial/barrial en sus modos de acción y participación. Éstas lograrían interpretar y potenciar las necesidades organizativas latentes en las comunidades movilizadas tales como la horizontalidad y la discusión de jerarquías, la democracia directa, la acción directa, la creación de tiempos y espacios propios y la dinámica asamblearia. ${ }^{8}$

En 1980 había entre cincuenta y sesenta CEBs en la Diócesis de Quilmes. Eran grupos de entre veinte y treinta jóvenes coordinados por un animador, elegido por ellos. Es decir, para ese año había más de mil jóvenes organizados y vinculados a la Iglesia a través de una Parroquia, en este caso la de Itatí. ${ }^{9}$ Se reunían para discutir cuestiones relativas al Evangelio y a la tarea evangelizadora, pero tomando como punto de partida la realidad que vivían. Así, se ocuparon de buscar soluciones a conflictos locales, ya fuesen vinculados a cuestiones personales o más generales. Estaban organizados en áreas de trabajo y había un responsable por cada proyecto que se llevaba adelante. ${ }^{10}$ En las comunidades impulsadas por el padre Berardo se promovía la descentralización de los sacramentos -bautismo, comunión- y la catequesis. ${ }^{11}$

Las Comunidades estaban organizadas en forma horizontal y

\footnotetext{
${ }^{8}$ De ninguna manera negamos la influencia que la organización sindical de base o por lugar de trabajo haya tenido en esta experiencia. Pero, por un lado no la consideramos determinante en última instancia; y por otro, el vínculo puede establecerse más con iniciativas sindicales que se proyectaban al trabajo barrial que con las estructuras organizativas únicamente fabriles (Vommaro, 2010 y 2015).

${ }^{9}$ Dato construido en base a las entrevistas realizadas y los textos de Cuenya (1984), Zibechi (2003), Aristizábal e Izaguirre (1988) y Vommaro (2010). También hay datos acerca de las Comunidades en esa época y su desarrollo posterior en la publicación Comunidades Eclesiales de Base. Memoria 20 años. Diócesis de Quilmes, Buenos Aires, 1997, que nos facilitó nuestra entrevistada Inés.

${ }^{10}$ Para ampliar acerca de la Creación de las Comunidades Eclesiales de Base, ver Berryman (1987).

${ }^{11}$ Raúl Berardo fue un sacerdote que se destacó entre los impulsores de las tomas y asentamientos de 1981 en Quilmes y Almirante Brown. Estaba al frente de la parroquia Nuestra Señora de Itatí en esos años y fue uno de los promotores de las Comunidades Eclesiales de Base a partir de 1977 en la zona.
} 
participativa y estaban basadas en el trabajo cotidiano a partir de los problemas concretos tanto de sus miembros como de la comunidad de fieles a los cuales se dirigían. A partir del número de Comunidades que existía en Quilmes en el último año de la década del setenta y el primero de los ochentas, podemos afirmar que entre cincuenta y sesenta jóvenes -los animadores- asumían trabajos de coordinación y tenían experiencia en dinámica de grupos, ejecución de proyectos y toma de decisiones. Estos jóvenes constituyeron el Consejo Pastoral de Comunidades que se reunía periódicamente:

Partíamos bien de las necesidades de este grupo de veinte, y que por ahí integraban en otros cuarenta, en otras hasta cien familias en los cuales...que se yo...el problema que tenemos hoy entre los veinte es que tal está enfermo...bueno, vamos todos a verlo, bueno, que tal se le murió no se quien...bueno vamos a acompañar a la viuda o problemas así muy concretos. ${ }^{12}$

Y hace que seas comunidad, donde eh ya el jefe no está más...es... se comparte, cada palabra tiene un valor y en eso valorás cada persona, cada historia. ${ }^{13}$

En los barrios conformados a partir de las tomas, la manzana se constituyó como la unidad organizativa mínima al menos en cuatro dimensiones: la espacial -distribución de los habitantes en el asentamiento y demarcación de los lotes-, la habitacional -construcción de las viviendas en principio unifamiliares en los lotes asignados-, la social -como espacio de sociabilidad e integración de nuevos vecinos- y la organizativa propiamente dicha -la asamblea inicial de la que emanaban todas las decisiones se realiza en este ámbito- (Vommaro, 2010).

Pueden distinguirse tres elementos principales en la experiencia de las

12 Entrevista a Raúl Berardo, sacerdote de Quilmes a partir de 1977.

${ }^{13}$ Entrevista a Inés, habitante de La Paz en 1981. 
tomas y los asentamientos durante la década del ochenta: por un lado, las formas organizativas definidas sobre todo por la horizontalidad, la democracia directa, la acción directa, la creación de tiempos y espacios propios, y la dinámica asamblearia. Por otro, las formas políticas que instituyen una politicidad de lo social que configura una militancia político-social (una política desde lo cotidiano) alternativa y a la vez alterativa, respecto de la lógica estatal. En tercer lugar, los procesos de subjetivación que se constituyen a partir de los espacios comunes o comunitarios que se configuran en la experiencia de autoafirmación que estudiamos.

Tanto las CEBs como sus animadores constituyeron una red organizativa importante que sostuvo, en gran parte, las tomas y los asentamientos sobre todo en los primeros meses. Numerosos testimonios refieren al padre Berardo como un impulsor de las tomas y los asentamientos. Además, la Parroquia Nuestra Señora de Itatí era un referente importante para quienes se acercaban a Solano desde zonas aledañas en busca de tierra. Allí se daban los números a los que correspondía cada lote, se reunían las CEBs y los animadores, y, una vez constituidos los asentamientos, el lugar funcionaba también como sede habitual de la Comisión Coordinadora que articulaba los nuevos barrios con los espacios que apoyaba este proceso.

A partir de nuestra investigación, podemos concebir, además, a las CEBs como espacios en donde se concentran y expresan las principales características de las formas organizativas que adoptaron los nuevos barrios. Sin embargo, es en el proceso de tomas y asentamientos -que en su dinámica de masificación desbordan a las CEBs- en donde estas formas organizativas, la lógica político-social y las nuevas subjetividades se expresan y potencian.

Por otra parte, las Comunidades tenían una doble dimensión. Por un lado, fueron espacios de refugio o contención para militantes de los setenta a los que la dictadura les había cerrado o restringido sus espacios de militancia. El amparo de la Iglesia Católica servía como resguardo para mitigar el peligro 
de la represión genocida sobre los activistas en la época. Por otro, las CEBs fueron también instancias de formación de nuevos militantes, surgidos en las dinámicas de organización comunitaria y territorial que se instituyeron a partir de los asentamientos.

De esta manera, la participación en ámbitos eclesiales, y especialmente en las CEBs, posibilitó, tanto en la Argentina como en muchos de los países de América Latina que vivieron dictaduras de los años setentas, canalizar acciones colectivas de resistencia, protesta y participación político-social ante la clausura de la política institucionalizada en clave democrática y la represión lanzada contra las organizaciones sociales y políticas. Al mismo tiempo esta participación, al politizar la vida cotidiana en el barrio, se constituyó en expresión del proceso de ruptura de las relaciones políticas basadas en la representación (Villareal, 1985; Levine y Mainwaring, 2001).

A partir de la experiencia de las CEBs, de las tomas y de los asentamientos, otros procesos barriales relevantes se fueron potenciando. Así, referentes comunitarios emergieron impulsando otros espacios de participación directa y producción comunitaria a través de nuevas tomas, asentamientos y otras iniciativas como los denominados fogones comunitarios. Tal es el caso de Agustín Ramírez, joven que vivía en el Barrio La Unión de Solano -lindero con el asentamiento San Martín que surgió de la toma de 1981-, quien creó los fogones como ámbitos de encuentro y participación de los jóvenes a nivel barrial. Su asesinato en junio de 1988, a la edad de 23 años, junto a uno de sus compañeros, Javier Sotelo, estuvo vinculado a su práctica político-social, si bien el crimen nunca se esclareció. ${ }^{14}$ Este asesinato fue tomado por diversos colectivos, grupos y organizaciones sociales como símbolo de represión policial hacia la militancia juvenil y además como suceso articulador de nuevas luchas y

${ }^{14}$ Agustín Ramírez fue asesinado junto a Javier Sotelo el 5 de junio de 1988 en las calles 826 y 898 de San Francisco Solano. Si bien el crimen permanece impune, hubo sospechas y han surgido pruebas que indican que estas muertes fueron responsabilidad de la Policía de la Provincia de Buenos Aires. 
demandas sociales a nivel local. Vemos así como en muchos casos, el entramado organizativo a nivel territorial y las formas de producción política juveniles pueden condensarse en trayectorias vitales de jóvenes que se convierten en referentes generacionales locales haciendo más intensas las redes sociales de organización e instituyendo temporalidades densas y situadas.

Luego de 1985, y más marcadamente de 1987, el proceso de organización de los asentamientos se modificó y se diluyeron sus espacios más visibles. A su vez, se generalizó un desencantamiento respecto a la política partidaria, que contrasta con el fuerte apoyo que el regreso democrático despertó inicialmente. ${ }^{15}$ Los colectivos territoriales debilitaron su confianza en que la política democrática y delegativa que se pretendió consagrar luego de 1983 era el camino para mejorar las condiciones de vida de la población y se sintieron cada vez más alejados de la lógica que reproducían los partidos políticos. De este proceso de desilusión y expectativas frustradas -que entre otros autores, Rinesi interpreta en su libro Seducidos y abandonados (1993)señalamos dos aspectos. Por un lado, prepara el clima social y político de descontento hacia lo estatal que permite la consolidación de las políticas neoliberales de los años noventa. Por el otro, impulsa la constitución de formas de producción política alternativas a la participación ciudadana mediada por el estado, que se basan en las modalidades políticas territorialmente situadas producidas en estos años.

\footnotetext{
${ }^{15}$ El desencanto con el sistema democrático se produjo en un proceso de pocos años, pero que encuentra diversas causalidades entre las cuales mencionaremos dos. Por un lado, la crisis económica y de la deuda que llegaron a su punto máximo con el proceso hiperinflacionario de 1989 y la entrega adelantada del poder por parte del presidente Raul Alfonsín a Carlos Menem. Por el otro, las implicancias de las leyes Punto Final y Obediencia Debida dictadas en 1986 y 1987 respectivamente, que fueron vividas socialmente como reversión de los denominados Juicios a las Juntas de 1985.
} 


\section{AÑos NOVENTAS: EL TERRITORIO EN PRODUCCIÓN DESDE LAS PRÁCTICAS DE AUTOGESTIÓN}

Según la perspectiva que proponemos en este artículo consideramos que la década de los noventas se extiende entre 1989 y 2001, delimitando un período que hemos caracterizado como larga década neoliberal (Vázquez y Vommaro, 2009). Este es un momento en el que podemos destacar al menos dos procesos en cuanto a las relaciones entre juventudes, políticas y territorios: por un lado, el ya señalado desencantamiento con las formas clásicas de la política expresadas en los partidos políticos, sindicatos y las instituciones del sistema político en general; por otro, este alejamiento de la política institucional es acompañado por una expansión de espacios alternativos de producción política, en general vinculados al trabajo barrial - territorial, a ámbitos sociales o culturales y a dinámicas que extendieron las aspiraciones hacia la horizontalidad, la autonomía y la participación directa, en discusión con la política estadocéntrica, la representación o delegación y el verticalismo.

En estos rasgos de las formas políticas producidas en los años noventas por los jóvenes organizados en diversos colectivos territoriales pueden rastrearse continuidades respecto a las maneras en las que se desplegó la politización en la década anterior. Aquí proponemos una interpretación que busca visibilizar las pervivencias y actualizaciones más que resaltar las supuestas novedades o discontinuidades en las modalidades de producción de las configuraciones políticas generacionales en el período. De esta manera, discutimos con algunas visiones clásicas que sostienen que lo característico de la década del ochenta era la participación en partidos políticos, sindicatos y centros de estudiantes como espacios legítimos y valorados de inscripción de las prácticas político-ciudadanas, mientras en la década del noventa estas formas organizativas mostraron serios límites para contener a las juventudes y expresar la formas de militancia política en general (Sidicaro y Tenti Fanfani, 
1998).

A partir de las investigaciones que aquí presentamos podemos identificar que la lógica de politización en el territorio que se consolida en los años noventas, expresa continuidades con las formas territoriales $\mathrm{y}$ comunitarias que estudiamos para los ochentas. Así, modalidades anteriores se reconfiguran potenciando una producción política que tiende más a la participación que a la representación, a la acción directa que a las mediaciones institucionales, a politizar afectos y relaciones cotidianas dinámicas que a acuerdos ideológicos fijos y cristalizados (Zibechi, 2003: 50 y ss.). En otros trabajos denominamos a esta lógica como político-social centrada en los procesos societales y sostuvimos que convive en el territorio -con tensiones y contradicciones- con la dinámica político-partidaria con componentes más estadocéntricos (Vommaro, 2010, 2013 y 2015).

En este proceso de consolidación de las configuraciones políticas territoriales y comunitarias con protagonismo generacional, la búsqueda de la autonomía aparece como elemento distintivo. Esta autonomía como horizonte de construcción política en tanto no dependencia de partidos políticos, sindicatos o iglesias y no reproducción de sus dinámicas de funcionamiento se potencia con el desarrollo de experiencias de autogestión que visibilizan la dimensión productiva del territorio. Para acercarnos a este tipo de experiencias trabajaremos con los jóvenes organizados en el Movimiento de Trabajadores Desocupados (MTD), del barrio Solano- Quilmes.

Este Movimiento surgió en el año 1997, aunque como sostuvimos en otros trabajos (Vommaro, 2010 y 2015) su génesis puede rastrearse en las formas de organización comunitaria y territorial que tuvieron lugar desde 1981 y se consolidaron en las tomas y los asentamientos que analizamos en el apartado anterior. De hecho, el MTD surgió en el barrio San Martín que fue producto de la ocupación de 1981. Al acercarnos a las características de los jóvenes que participan en el MTD de Solano estamos distanciándonos, además, 
de los estudios que enfocan a los jóvenes de los barrios pobres del Gran Buenos Aires desde las categorías de exclusión, desafiliación, vulnerabilidad y marginación y los conciben sin capacidades, condenados a la fragilidad y la sobrevivencia .

Si bien la experiencia de participación, organización y producción de los jóvenes que se compusieron en el MTD de Solano se produjo en una situación signada por la pobreza, la desigualdad social y el desempleo que se agudizaron por la implementación de las políticas neoliberales predominantes en los años noventas, en nuestro trabajo de campo pudimos descubrir que hay jóvenes que, aún en estos escenarios, potencian sus capacidades para construir organizaciones sociales que despliegan propuestas alternativas en lo productivo, lo político y lo subjetivo. Es decir, que son protagonistas de procesos instituyentes, afirmativos, disruptivos e innovadores de politización del espacio y producción en el territorio. Dicho esto, podemos avanzar en la interpretación de algunos rasgos característicos de las formas políticas que produjeron los jóvenes que se organizaron en el MTD de Solano en la segunda mitad de la década del noventa.

\section{Darío Y MaXi como símbolos DE LA MiLitancia JUVENIL TERRITORIAL}

Para hablar de la dimensión generacional del MTD de Solano resulta oportuno comenzar por analizar las figuras de Darío Santillán y Maximiliano Kosteki que fueron adoptadas como símbolos de la militancia en las organizaciones de trabajadores desocupados - no sólo entre los jóvenes, pero fundamentalmente entre ellos- luego de su asesinato en junio de 2002.

Santillán y Kosteki ("Darío y Maxi”, como los nombraban sus compañeros) fueron asesinados en la represión a una manifestación e intento de 
corte del Puente Pueyrredón, que une la ciudad y la provincia de Buenos Aires, el 26 de junio de 2002 durante la presidencia de Eduardo Duhalde. Darío tenía 21 años y Maxi 22 cuando los mataron. Los episodios que rodearon su muerte se conocieron con el nombre de Masacre de Avellaneda.

Ambos se convirtieron en símbolos y referentes de la militancia territorial, denominada por algunos piquetera. Por ejemplo, el MTD de Guernica, donde militaba Maxi, pasó a llamarse Maximiliano Kosteki luego de la masacre. En 2004 surgió el Frente Popular Darío Santillán, que agrupó a varias organizaciones de desocupados -y también de otro tipo-, especialmente de la zona sur del Gran Buenos Aires y La Plata. Por otra parte, en septiembre de 2009 nació la Coordinadora de Colectivos Maximiliano Kosteki, que agrupó a organizaciones territoriales que años atrás se autodenominaban como de trabajadores desocupados. Entre las organizaciones que integraban esta Coordinadora estaba el MTD de Solano.

Dos caracterizaciones pueden servirnos para comprender el tipo de recuperación de las figuras de Darío y Maxi que se produjo entre los Movimientos de Trabajadores Desocupados, incluido el MTD de Solano. Por un lado, el Frente Popular Darío Santillán (FPDS) decía desde su sitio web acerca de Darío que:

fue y es un referente muy importante y sintetiza los valores humanos y la conciencia política de las jóvenes generaciones que, desde un compromiso concreto con las reivindicaciones más urgentes de nuestro pueblo, luchan con vocación de impulsar cambios revolucionarios. ${ }^{16}$

Por su parte, la Coordinadora de Colectivos Maximiliano Kosteki expresaba en la "Semblanza de Maxi” que:

Maximiliano Kosteki era un joven de 22 años que estudiaba el

${ }^{16}$ Tomado de FPDS. ¿Qué es el Frente Popular Darío Santillán?. 2007. 
secundario con orientación artística para ingresar a la Facultad de Bellas Artes. Había realizado un curso de escultura y estudiaba pintura, dibujo y piano. También participó de un taller literario en Lomas de Zamora que actualmente lleva su nombre. Vendía flores, cuidaba perros y trabajaba en lo que se presentaba, pero siempre dibujaba, pintaba y escribía. Además hacía malabares, capoeira, tocaba el bajo, la flauta dulce y la armónica. El $1^{\circ}$ de mayo de 2002 participó de su primera manifestación en Plaza de Mayo [...] Ese día conoció los proyectos del Movimiento de Trabajadores Desocupados -MTD- de Guernica: mantener un comedor, cuidar una huerta, una biblioteca, una panadería, etc. Comenzó a ir a las reuniones y participar en las actividades hasta que llegó su primer y último corte de ruta. Dos semanas antes del 26 de junio había expuesto 20 de sus obras y la noche anterior escribió: “miro mucho más de lo visible”. El 26 de junio de 2002 [...] las fuerzas policiales realizaron una gran represión [...] persiguen a dos jóvenes desarmados en la estación de tren de Avellaneda y los asesinan a sangre fría. Ellos son Maximiliano Kosteki y Darío Santillán. Hoy día sus vidas y sus nombres son retomados por diversas organizaciones como señal de que la muerte no pudo parar el impulso creador de estos jóvenes. ${ }^{17}$

Vemos en estos dos textos que se recupera una imagen de estos jóvenes vinculada tanto a los valores, la conciencia política y el compromiso -en el primer caso-, como a las cuestiones de la vida cotidiana, el acercamiento casi casual a la militancia, la expresión artística, los afectos, la participación política desde lo barrial y concreto, y el impulso creador. Esta recuperación está despojada de conflictos y contradicciones, alimentando una memoria heroica vinculada a resaltar más la politización territorial desde lo cotidiano expresada en jóvenes emblemáticos, que los contrastes propios de estos procesos.

${ }^{17}$ Tomado de Colectivos Maximiliano Kosteki. Semblanza de Maxi. 2009. 
En este punto podemos incluir un elemento que contribuye a la fundamentación de nuestra perspectiva de abordar las configuraciones políticas a nivel generacional en base al trabajo con colectivos juveniles territoriales en el mediano plazo. Nos referimos a las relaciones simbólicas que se establecieron en el MTD Solano entre estos jóvenes asesinados en 2002 y Agustín Ramírez, asesinado en julio 1988, como dijimos impulsor de la organización territorial en la zona en los primeros años ochentas.

Esta relación se expresó, por ejemplo, en la realización de un mural pintado en la esquina de la calle 891 en el Barrio San Martín -a pocos metros del galpón que servía como sede del MTD de Solano- en que aparecían las caras de Darío y Agustín y, abajo, las fechas de sus asesinatos. Es decir, las luchas del barrio estaban encarnadas por jóvenes que desplegaron su militancia territorial allí mismo o en zonas cercanas y fueron asesinados por la policía a raíz de su participación política. La configuración generacional que tendía puentes y de alguna manera igualaba experiencias separadas por más de diez años se nutría tanto de la militancia situada anclada en procesos cotidianos, como en haber sido muertos por fuerzas policiales mientras desplegaban su práctica. Estos elementos cimentaban la intención multiplicadora de la memoria actualizada y territorializada la cual será también muy importante para los jóvenes del siguiente apartado.

\title{
5. EL POST-2001: MODOS GENERACIONALES DE POLITIZACIÓN TERRITORIAL DESDE LAS DIVERSIDADES
}

\begin{abstract}
Abordaremos en esta sección algunos aspectos socio espaciales, performativos, subjetivos y políticos que se encuentran estrechamente interrelacionados en las dinámicas de despliegue de la politización generacional territorialmente configurada. Así, aquí nuestro análisis constituye
\end{abstract}


un acercamiento a las expresiones y articulaciones de la diferencia en situaciones de producción de espacialidades y a las memorias que las intervienen. Como momento de eclosión de estos procesos tomamos la crisis producida en la Argentina a fines de 2001 en tanto fenómeno desbordante de la vida social que, de manera indirecta, derivó en la consolidación, reproducción y emergencia de prácticas de politización comunitaria y territorial desplegadas entre los intersticios de la militancia partidaria y las formas de producir política alternativizando las instituciones legitimadas del sistema político. ${ }^{18}$

El barrio se consolidó en esta época como una de las principales unidades territoriales de organización popular y desde allí emergieron la mayoría de las acciones colectivas de resistencia. Este hecho favoreció la consolidación de redes sociales de solidaridad y afinidad construidas entre sujetos diversos igualados por la experiencia de crisis general. En esta situación los modos de ser y actuar de las y los jóvenes tuvieron un lugar relevante en tanto promotores de vías alternativas de producción política molecular que implicaron también modos alternativos de comprender y vivir las espacialidades singularizadas.

Prácticas de base comunitaria de diversa índole resultaron ser potentes en términos de creatividad, solidaridad y resistencia, en lo que serían expresiones de producciones políticas gestadas en los noventas, década signada por la auto-organización y la participación directa en clave espacial y situada. Así, en el municipio de Quilmes, parte de las nuevas generaciones se agruparon en torno a procesos configurados en al menos tres temporalidades: la de la crisis de aquel presente, la del pasado inmediato de organización de los años noventas y aquella más lejana forjada en las tomas y asentamientos de la década del ochenta, cuyas afectividades dieron sentido y cohesión a las acciones grupales territorializadas.

\footnotetext{
${ }^{18}$ Trabajamos estos procesos en Vommaro, 2012.
} 
Una de las expresiones de este proceso de politización territorial en clave generacional luego de la crisis de 2001 que nos interesa destacar aquí son las organizaciones juveniles indígenas que se desplegaron en Quilmes. Nuestro interés por incluir esta experiencia en este artículo se sustenta sobre todo en dos elementos. Por un lado, porque, aunque no del todo consolidados en aquellos años, estos colectivos lograron reproducir, diversificar y sobre todo recrear y resignificar algunas de las características más sobresalientes del movimiento indígena clásico. Por el otro, porque el estudio de las organizaciones juveniles indígenas nos abre un conjunto de cuestiones que complejizan las interpretaciones de los procesos de politización territoriales con perspectiva generacional incorporando una diversidad de concepciones y configuraciones espaciales, a la vez que problematiza el lugar de la dimensión generacional en los procesos de politización a nivel subjetivo.

La sanción de la ley № 26.206 del año 2006 que reglamentó la Educación Intercultural Bilingüe en el sistema educativo argentino, renovó la visibilidad de los integrantes de los pueblos indígenas en la agenda pública como agentes activos de la acción política ${ }^{19}$. Esto implicó a la vez amplias discusiones en torno a la reivindicación de derechos étnicos y las posibilidades del sistema educativo para reconocerlos e incorporarlos. Hasta ese momento, los procesos de organización juvenil desarrollados al interior del denominado movimiento indígena, eran prácticamente desconocidos. Pese a ello, los grupos conformados por jóvenes indígenas existían produciendo sus propias dinámicas de participación, conocimiento y auto-organización. Asimismo, las características de los procesos de politización de los jóvenes indígenas constituyeron y constituyen elementos significativos que demandan un análisis singular en el marco de las investigaciones acerca de las formas de militancia y

${ }^{19}$ La visibilidad de los pueblos indígenas, como bien señala Kropff (2004), había encontrado una fuente de legitimación pública a partir de la inclusión en el censo de 2001 de la dimensión de la etnicidad como variable para caracterizar la estructura socio-demográfica argentina. 
participación juvenil a nivel territorial.

\section{JóVENES INDÍGENAS EN LA CIUDAD: MULTIPLICIDADES TERRITORIALES Y SUBJETIVAS}

Las juventudes indígenas en situación urbana, además de elaborar una visión multilocalizada e híbrida de la realidad social, despliegan formas singularizados de militancia, participación política y producción territorial desde las cuales las nociones de juventud -y generación-, política y territorio son reconfiguradas no solo respecto al sujeto no indígena -otro-, sino también en lo que se refiere a las relaciones que establecen con sus propios antepasados. Pensamos que la incorporación de este tipo de diferencias como parte de la diversidad de los movimientos sociales -tal como expresara el brasilero Leonardo Boff- implica la aceptación de complementariedades y convergencias construidas no desde la homogeneidad, sino a partir de la multiplicidad de cosmovisiones y prácticas otras (Boff citado por Escobar, 2003).

La noción de juventud indígena tiene un pasado breve aunque las juventudes indígenas en tanto actor social pueden ubicarse mucho antes (Cruz, 2012). Contando con excepciones como los trabajos de Kropff (2004, 2005 y 2011), las ciencias sociales se enfocaron en abordar el movimiento indígena desde una visión adultocéntrica. Es decir, la perspectiva juvenil y la dimensión generacional no han sido temas abordados de manera directa en los pueblos indígenas hasta hace algunos años.

[...] hablar de indígenas siempre implicó hablar de los líderes o chamanes, oradores o curanderos, artesanos o milperos, macehuales. El sujeto indígena de la literatura etnológica siempre ha sido el adulto varón. Pero hablar de los indígenas ha significado hablar poco de los niños indígenas adolescentes o de la gente joven, los que son el futuro 
de la población no han estado involucrados en términos económicos ni culturales. (Feixa, 2006: 7-8)

Tanto factores sociodemográficos (una mayor visibilidad de la población indígena que habita la Argentina en los censos y estudios poblacionales al menos desde 2001 evidencia con más facilidad elementos no considerados antes), como la presencia de singularidades expresivas (que suelen diferenciarse de las de sus padres y antepasados), la expansión de los estudios de juventudes hacia áreas poco trabajadas antes y elementos más estratégicos vinculados con el hecho de que constituyen un nuevo sector de consumo o una población a contemplar por el sistema socioeducativo (Pérez, 2011), influyeron en el viraje hacia el estudio de las juventudes indígenas rurales y urbanas y sus diferentes prácticas expresivas en los últimos diez años. ${ }^{20}$

En la experiencia que tomamos aquí, la de los jóvenes de la comunidad Qom-Yapé del barrio de Bernal en Quilmes, sus prácticas de participación socio-territorial comunitaria han estado enmarcadas por la transmisión pedagógica de conocimientos dirigidos a promover la puesta en común de su experiencia singular y de los modos propios de adaptación, interacción, integración y cambio en contextos urbanos. Este intercambio con los espacios sociales extracomunitarios ha estado mediado por algunas actividades desde las que los jóvenes auto reconocidos como indígenas -más adelante ahondaremos en este tema- promueven la realización de charlas en colegios de Quilmes y alrededores, lo que constituye una transmisión de doble vía en la que comparten aquello que, en algunos casos, aún se encuentran conociendo e

\footnotetext{
${ }^{20}$ Consideramos aquí trabajos como los de Laura Kropff (2004, 2005 y 2011), quien abordó los cruces entre juventudes, etnicidad y dinámicas urbanas para el caso de los Mapuche en la Argentina; y los de Flor Edilma Osorio (2005), para el caso colombiano. En el caso de Kropff, además, aborda experiencias de politización de jóvenes indígenas en la ciudad incorporando dimensiones estéticas, artísticas y expresivas y estudia los procesos de reivindicación territorial, lo cual acerca sus planteos a los problemas que aquí abordamos.
} 
incorporando en sus propios modos de ser, estar y vivir respeto a su pertenencia comunitaria. En estas charlas se comparten con los estudiantes que participan experiencias de lo que implica ser un indígena nacido en la ciudad, y pertenecer al pueblo Toba-Qom particularmente. Esto incluye la puesta en común de ciertos saberes y prácticas considerados ancestrales y exclusivos de la comunidad en un ejercicio en el que se construyen procesos discursivos en los que emerge una etnicidad militante actualizada. Habría así una reinvención de la etnicidad juvenil que se alimenta, en gran parte, del anclaje en el pasado y en el territorio del que provienen padres y abuelos pero que se replica, instituye y emerge en las territorialidades otras configuradas por el espacio urbano.

Las personas, familias y/o comunidades migradas al Gran Buenos Aires desde provincias del Noreste y el Litoral argentinos lograron constituir una red que conecta al pueblo indígena Qom en contexto urbano pero que extiende su alcance multidireccional hasta los territorios desde dónde provienen originalmente al igual que hacia otras territorialidades. En cada uno de los nodos de la red, se encuentran comunidades, en cuyos jóvenes se evidencian modos de ser y estar singulares pero con un hilo conductor común que las identifica y moviliza en tanto parte de un grupo social y generacional común. Estas estrategias sociales de ser, estar y aparecer ante y con otros basadas en la dimensión espacial dependen de la ligazón al territorio en tanto éste, sobre todo en sus aspectos simbólicos y subjetivos, configura en gran parte sus prácticas políticas y sus procesos de subjetivación. En Quilmes esto implica la articulación con otras redes y organizaciones comunitarias con las que se han creado tejidos de comunicación y acción permanentes como por ejemplo el trabajo conjunto con las personas Qom que habitan en el barrio denominado Villa Iapi.

La participación juvenil en la dinámica comunitaria está enmarcada por un proceso vital por el que debe pasar todo hijo de migrante indígena en la ciudad: el llamado auto reconocimiento (indígena). Éste se constituye como 
una etapa vital, problemática y no siempre resuelta, que se configura a partir de la decisión de hacer parte -o no- del grupo étnico al que pertenecen los parientes de primer y segundo grado. No es un proceso fácil; el auto reconocerse como parte de una comunidad indígena en la ciudad conlleva consecuencias en términos de capital sociocultural que los niños y jóvenes comprenden y problematizan de manera recurrente.

Yo primero no me quería reconocer indígena, no quería saber nada del tema, rechazaba todo... no es por rechazo a mi pueblo sino por miedo a la discriminación, tenía 20 años: una por el miedo de ser y de vivir en un barrio humilde (...) nosotros los pobres ya nacemos con una mochila que es la pobreza por más que no nos guste. "Sabemos manejar ese tema” pero después ser indígena es, para mí lo pensé, otra mochila; como que llevamos dos cargas, dos mochilas pesadas. Yo decía: "si me reconozco va a pasar esta cosa y esta otra, no, no quiero que me discriminen por ser o reconocerme indígena”. ${ }^{21}$

La relación emocional-territorial emerge así como vínculo simbólico entre generaciones. Por un lado, los padres que migraron desde las provincias de Chaco o Formosa teniendo alrededor de 20 años de edad -en algunos casos menos-, dejaron en el territorio de origen su historia, sus parientes y sus rastros. Esto constituye un pasado cercano que los interpela de manera constante, lo que se evidencia cuando hablan de estos lugares como "su tierra", "su territorio”, sintiéndose partícipes activos de las demandas permanentes que sus compañeros -hermanos en la lógica comunitaria indígena- de zonas rurales realizan en términos territoriales. Al igual que otros municipios del Gran Buenos Aires, el de Quilmes fue escenario de periódicos flujos de migración campo-ciudad por parte de indígenas provenientes de diversas provincias

${ }^{21}$ Entrevista a Hernán Ávalos, joven Qom de Quilmes. 
argentinas durante la segunda mitad del siglo $\mathrm{XX} .{ }^{22}$ La migración de estas familias al Conurbano bonaerense les significó transitar una situación singular en la que los mecanismos de vínculo entre pares pasaron de ser en su mayoría comunitarios y rurales - con fluctuantes intercambios con la ciudad-, a desplegarse en ámbitos más amplios de relación social y de territorialización, desterritorialización y reterritorialización permanentes.

Por otro lado, las y los jóvenes Qom nacidos en contexto de ciudad tramitan la relación con el pasado compartido por sus padres, con la historia y con los vínculos filiales y étnicos de una forma distinta. El hecho de que su desarrollo y formación se hubiese realizado en contextos urbanos y que conocieran tardíamente aquellos territorios en los que originalmente vivió su pueblo y del que provinieron sus padres - hay incluso algunos jóvenes que no han visitado nunca estos lugares-, no fue impedimento para que muchos reconocieran, asumieran y adoptaran lo que podemos denominar una etnicidad activa, visibilizada y militada como espacio de reafirmación subjetiva, vital, biológica, además de socio-comunitaria.

En el caso de los y las jóvenes Qom de la comunidad Yapé, sus formas de participación desbordan los límites de la pertenencia indígena, si bien la etnicidad es parte constitutiva de sus modos de ser y estar en relación con otros. Al asumir una etnicidad activa los y las jóvenes encarnan también los rasgos constitutivos de la comunidad que los cobija la cual se considera autónoma, cooperativista y solidaria -elementos que comparten con los grupos analizados en los apartados anteriores de este artículo-, por lo que son las maneras de expresar esos modos de ser y estar singulares y potentes las que toman relevancia en un contexto de hibridación cultural y despliegue de experiencias políticas situadas. En este sentido, un elemento que aparece

${ }^{22}$ Entre todos los grupos indígenas en territorio argentino, el pueblo Toba-Qom, ubicado principalmente en las provincias del Chaco y Formosa al noreste del país, posee un mayor porcentaje de integrantes de primera y segunda generación que han migrado a la provincia de Buenos Aires junto a los Wichí y los Mapuche. 
frecuentemente en las comunidades Qom en contexto urbano es que sus jóvenes visibilizan sus modalidades culturales $-\mathrm{y}$ políticas- híbridas y las expresan a través de su estética corporal y de formas del decir y del hacer que no reproducen los modos establecidos por otras organizaciones urbanas o por sus padres en sus territorios de origen.

Una expresión de estas formas culturales y políticas singulares, configuradas al calor de procesos de territorialización y politización diversos en los que la dimensión estética es parte fundamental de sus dinámicas, es el grupo de rap M.L.V Crew, de la ciudad de La Plata, cuyos integrantes, hijos de migrantes Qom, adoptaron el estilo Hip Hop para transmitir sus singularidades (Tamagno, Maidana y Colángelo, 2013):

Mis manos fueron hechas para empuñar un arco y una flecha entre las líneas estrechas de esta vida y una cultura casi dada por perdida, que nunca olvida la herida y una pesadilla, golpea la otra mejilla, pero en el horizonte brilla la esperanza, alzando mi puño al viento una lanza en honor a los que en paz descansan, hoy hablo de mi barrio, el orgullo de gente por hacer escultura de barro, pero éste es el suelo que piso porque dios así lo quiso y sé que la comunidad es mi paraíso. ${ }^{23}$

En esta situación de tensiones, continuidades, rupturas e hibridaciones,

${ }^{23}$ Fragmento del tema musical A fuerza de MLV CREW, registrado en la Sociedad Argentina de Autores y Compositores de Música (SADAIC) con el No 808687. 
los y las jóvenes no dejan de construir espacios expresivos generando particulares modos de actuación políticos situados y configurados territorialmente. Es decir, espacios otros en los que se transitan vías desancladas de la semantización, del “todo significa o debe significar”, donde se reinventaría la política como ámbito en el que convergen singularidades que devienen en tipos diversos de sociabilidades y espacialidades situadas (Daza, 2008).

En ocasiones también la acción excede a la palabra ocupando espacios que desbordan los significados establecidos y reconfiguran sentidos en un contexto de cruce con diversas multiplicidades. Una de ellas es la estética como expresión -y a la vez productora- de afectividades que se despliegan a través del performance como espacio de lo no dicho, de la expresión que desborda a la verticalidad del signo ocupando ámbitos otros, transgresores. No se trata sólo de la dramatización teatral de algún acontecimiento, sino también de la utilización y apropiación de herramientas espacio-temporales que entran en juego con la puesta en escena -en cuerpo, en sentires, en afectos- de la acción política, constituyéndose en epicentro de múltiples sensibilidades e interpretaciones. La estética, en tanto expresividad no determinada, aparece así como una herramienta de sustracción al ejercicio establecido del poder en tanto transita las vías de lo instituyente, del acontecimiento, de los alcances de las afectividades y sus formas.

En síntesis, las experiencias de politización juvenil que aquí abordamos instituyen como parte de sus prácticas y producciones expresivas las disputas por el control, la apropiación y la reinvención del territorio. De allí que sean expresiones significativas de un tipo de producción política singular configurada a partir de la dimensión espacial, devenida territorial, lo que permite inscribir sus acciones singulares y situadas en la memoria territorial y comunitaria de Quilmes. Así, los modos de expresar las configuraciones políticas generacionalmente gestadas (Vommaro, 2015) se entraman en 
vínculos afectivos y de memoria inscriptos en territorios diversos, de la diferencia, que expresan los procesos comunitarios a partir de las dinámicas políticas interpretadas en clave territorial y generacional.

\section{Palabras FinAles}

Las experiencias organizativas abordadas en este artículo además de mostrar procesos de juvenilización de ciertas acciones que suelen ser atribuidas a los adultos, visibilizan algunas formas de interacción propositiva por parte de sujetos política y espacialmente agenciados. Estas formas de espacialidad se configuran también a partir de tránsitos y devenires que consiguieron reconfigurar las búsquedas de localización estática superando las fronteras del aquí y el allá, del centro y la periferia, del espacio vivido, el espacio aprendido y el espacio social, dimensiones que se imbrican a través de la construcción tanto simbólica como material del territorio. El lugar recordado -jóvenes de pueblos originarios- tanto como el lugar producido e imaginado -tomas, asentamientos, espacios ocupados y de producción comunitaria- se constituyen así en un eslabón simbólico para las experiencias de organización territoriales vistas, que direccionan sus prácticas y reconstruyen sus cosmovisiones y singularidades en pos de la producción política de territorio en temporalidades entramadas en la lógica espacial.

Estos modos de producción política juvenil han logrado interpretar y potenciar, con matices diversos, el giro espacial que caracteriza la dinámica social contemporánea y que explicamos al inicio de este trabajo. Por un lado, mediante el despliegue de acciones colectivas que suponen la comprensión de espacialidades devenidas en la posibilidad de otras territorialidades, tales como la experiencia de las tomas y los asentamientos promovidos por las CEBs en los años setentas y ochentas. Por el otro, a partir de la ocupación de los 
espacios públicos por parte de los MTDs en los noventas -que implicó la resignificación del barrio como territorio híbrido entre lugar de producción y lugar de reproducción-. En tercer término, a través de los modos subjetivos y expresivos a partir de los que se producen espacios otros por parte de los jóvenes Qom en contextos de ciudad, cuyas acciones expresan la superposición de múltiples capas territoriales que los intervienen y constituyen y que ellos reconfiguran y recrean. En estas diversas experiencias pudimos ver como la producción de territorio se constituye como dispositivo político producido y productor de acciones colectivas juveniles diversas.

Si bien los casos abordados no permiten realizar generalizaciones, podemos sostener que en las tres décadas analizadas es posible identificar ciertas continuidades y reconfiguraciones en términos organizativos, en las prácticas políticas juveniles y en las singularidades territoriales ancladas a momentos específicos. Esto nos permite reconstruir un recorrido de las juventudes organizadas en el partido de Quilmes en la mediana duración, según las décadas, los territorios y las experiencias aquí propuestas.

El cierre de los canales de participación y diálogo institucionalizados que se diera durante la dictadura militar, condujo a que la autonomía emergiese como una de las búsquedas más visibles de las organizaciones sociales en los años ochentas. Las Comunidades Eclesiales de Base impulsaron la configuración de una organización basada en la participación directa, la discusión de las jerarquías establecidas y la deliberación colectiva, esbozando la mayoría de los elementos que luego permitirán hablar de formas de organización horizontales. Esta aspiración a la horizontalidad y a la participación directa por sobre la representación y la delegación, fueron características que prevalecieron en los Movimientos de Trabajadores Desocupados de los años noventas, aunque con algunas variaciones significativas propias de las singularidades de cada experiencia.

Asimismo, a partir de cambios en la coyuntura política general que se 
expresan en el territorio, podemos distinguir un proceso de disolución de la organización territorial surgida de las tomas y los asentamientos entre 1985 y 1989. Quizá la experiencia de los fogones comunitarios y la organización territorial que integraba Agustín Ramírez sean una de las últimas expresiones visibles de las organizaciones comunitarias construidas en Quilmes en los primeros años ochentas.

En los años noventas el espacio barrial además de potenciar la aspiración por la autonomía, incorporó a la práctica política procesos productivos desplegados en dimensiones territoriales y comunitarias que avanzaron en la institución de lógicas productivas alternas. El barrio y la forma en que éste fue reformulado como lugar de tránsito entre un estado de ocupación y otro de desocupación, implicó de manera más clara la búsqueda de formas alternativas de producción y subsistencia. Se trató de un proceso de resignificación de lo público a través del trabajo comunitario que implicó que los procesos productivos se trasladasen al barrio -producción en el territorio-, rasgo que caracterizó de manera marcada las experiencias organizativas y territoriales de esta década.

El énfasis de la organización barrial se mantuvo y potenció en el contexto de la crisis de 2001. La diversificación, la auto-organización y la memoria en clave territorial emergieron en este periodo como elementos cohesionadores de procesos y prácticas de diferente índole. Esto puede apreciarse, por ejemplo, en el hecho de que diferentes organizaciones de estos años constituyeron como referentes a los jóvenes asesinados o perseguidos por el estado en las décadas anteriores. Asimismo, las tomas, luchas situadas y las prácticas políticas comunitarias y territoriales lograron imponerse al olvido en una disputa por la memoria territorial en la que día a día se reconstruyen hitos que dan sentido a la acción colectiva y son a su vez reconfigurados por ésta.

La memoria se constituyó así como agente productor de subjetividades en resistencia que desplegaron antagonismos en el territorio cuyos límites tanto 
temporales como espaciales fueron desbordados logrando convivir en el aquí y el ahora con espacialidades y temporalidades anteriores vitalizando las experiencias de organización juveniles situadas. El territorio logra así, exceder la bidimensionalidad estática instituyendo una concepción integral de las espacialidades en la que tanto éste, como las capas y cuerpos que lo habitan, requieren relacionarse de forma permanente con otros tal como lo haría un organismo viviente (Echeverri, 2004).

La multiespacialidad de los militantes es un rasgo común en las tres décadas vistas en tanto sus acciones responden a procesos anclados a lugares en los que se está sin estar por completo -heterotopías en palabras de Foucault (1984)-, pero que inciden en las subjetividades y en los modos en que éstas se producen y expresan ${ }^{24}$. Asimismo, la experiencia multiterritorial de los jóvenes Qom constituye otro ejemplo al respecto en el que además del componente temporal anclado a las memorias construidas, el territorio vivido, el territorio migrado -transitado-, el territorio aprendido, el territorio producido y el territorio imaginado confluyen en la constitución de prácticas que emergen en esa multiespacialidad. Esto implica buscarse, reconocerse y agruparse también a partir de la reproducción reinterpretada de rituales y creencias que fueron aprehendidos de maneras indirectas pero que moldearon los modos de ser generacionales de una comunidad indígena en espacios periurbanos.

Al igual que la multiespacialidad, otras singularidades comunes a las experiencias abordaras son: la institución de lo común como elemento condensador de objetivos en los que la autogestión y la reciprocidad son reconfiguradas como herramientas disruptivas de las lógicas dominantes, el reconocimiento de las afectividades compartidas como dimensión de politización entre los jóvenes integrantes de los colectivos situados, la auto-

\footnotetext{
${ }^{24}$ Las heterotopías son espacios en los que son reflejados aquellos valores que pueden ser reconocidos en uno mismo pero en el que también se yuxtaponen las relaciones a la vez que se entremezclan, problematizan y emplazan (Foucault, 1984).
} 
organización y búsqueda de autonomía que, a la vez, no desconoce una relación ambivalente y estratégica con el estado y las instituciones.

Resaltamos también la coexistencia en los territorios abordados en Quilmes de una yuxtaposición de capas espaciales diversas ancladas en procesos históricos de larga data (Lefebvre, 2013), lo que permite pensar la interculturalidad, el trabajo comunitario y la constitución de redes, desde una perspectiva relacional de composiciones y articulaciones con tiempos y espacios disímiles que, sin embargo, logran pervivir y articularse. Asimismo, tanto la dimensión estética de las prácticas juveniles, como las acciones pedagógicas hacia afuera de los grupos caracterizadas por las herramientas expresivas que las configuraban, fueron un común denominador en las tres décadas estudiadas. Siguiendo a Williams (1980), y aunque esto deberá quedar para un próximo trabajo, identificar los elementos arcaicos, residuales y emergentes puede ser una vía fructífera para interpretar las dinámicas de producción política territorial situada y las múltiples temporalidades $\mathrm{y}$ espacialidades que se entraman en las configuraciones generacionales aquí estudiadas.

Así, experiencias que perviven y se actualizan a partir de prácticas y narrativas territorializadas a lo largo de tres décadas se entraman recuperando saberes y aprendizajes a partir de los cuales se constituye lo emergente -la innovación- y se precipita lo arcaico que se demuestra no útil en las nuevas coyunturas. La temporalidad de los años ochentas con las tomas de tierras y la construcción de los asentamientos instituyó un territorio que se tornó intensamente productivo en los años noventas y se pluralizó en los dos mil ${ }^{25}$. De esta manera, podemos considerar las tres temporalidades y las tres inflexiones de producción territorial estudiadas aquí en clave de superposición

${ }^{25}$ En otros trabajos (Vommaro, 2012 y 2015) abordamos estas continuidades y rupturas que entraman lo temporal y lo espacial desde el análisis de las redes sociales de organización territorial, que por razones de espacio no profundizaremos aquí. 
y sedimentación de tiempos y espacios atravesados por disrupciones y emergencias que configuran la dinámica de los conflictos políticos territoriales que se expresan en clave generacional.

En resumen, en las experiencias históricas de los territorios abordados se condensan diversos procesos políticos singulares que fueron producidos por jóvenes y organizaciones juveniles con una intensidad suficiente como para producir, reconfigurar y tensionar situadamente las lógicas dominantes a lo largo de tres décadas. La ubicación geográfica de Quilmes respecto a la Ciudad de Buenos Aires resulta clave en este proceso singular en tanto es una zona del sur del Conurbano con un desarrollo fabril importante desde los años setentas, lo que la convertiría en lugar de establecimiento de los migrantes que no lograron quedarse en la Capital Federal o fueron expulsados por los procesos de segregación espacial constantes en el período. Además, Quilmes se encuentra ubicada entre las ciudades de Buenos Aires y La Plata -capital de la Provincia de Buenos Aires-, lo que la convierte en lugar de tránsito obligado y fluido.

Encontramos, asimismo, que hay diferentes formas de comunicación entre los barrios en los que se desplegaron las experiencias revisadas aunque hayan acontecido en décadas diferentes. La memoria territorial de Quilmes desde las tomas y los asentamientos de los años ochentas, los talleres productivos de los noventas y las comunidades indígenas en el post 2001-, puede identificarse en los elementos compartidos por los grupos abordados en este artículo quienes aún hoy conviven en el territorio y comparten procesos de lucha, comunitarismo y reinvención de lo político en clave generacional, signados por las afectividades singularizadas.

Reconstruimos así un hilo que puede vincular prácticas políticas generacionalmente situadas y distanciadas temporalmente, constituyendo una cartografía de las experiencias comunitarias juveniles, un mapeo exploratorio de las espacialidades y afectividades de la política barrial en Quilmes con perspectiva diacrónica. Lo hicimos asumiendo que todo espacio políticamente 
producido deviene territorio en el que se despliegan las diferencias y las potencias sociales, en este caso interpretadas en clave generacional. A su vez, a partir de nuestro trabajo, sabemos que en los procesos de producción y politización territoriales habitan modalidades de institución de formas políticas con la potencia suficiente como para permear y marcar, capa por capa, los sustratos situados y superpuestos que instituyen la persistencia de la organización territorial generacionalmente configurada.

\section{REFERENCIAS BIBLIOGRÁFICAS}

Blanco, R., Vázquez, M., Vommaro, P., Núñez, P. y Larrondo, M. (2014). "Revisitando la década del 80: una lectura sobre la participación juvenil en los albores de la recuperación democrática argentina”. En IV Reunión Nacional de Investigadores/as en Juventudes de Argentina (ReNIJA), Villa Mercedes, San Luis, Argentina. Recuperado de http://www.redjuventudesargentina.org/attachments/article/10/GT\%202 \%20Indice\%20y\%20Ponencias.pdf

Colángelo M., Maidana, C. y Tamagno, L. (2013). Ser indígena y ser joven. Entre la etnicidad y la clase. Revista Desacatos (42), pp.131-144.

Cruz, T. (2012). El joven indígena en Chiapas: el re-conocimiento de un sujeto histórico. LiminaR vol.10 No.2 San Cristóbal de las Casas.

Cuenya, B. (1984). Condiciones de hábitat y salud de los sectores populares. Un estudio piloto en el asentamiento San Martín, de Quilmes. Buenos Aires: Ed. CEUR.

Daza, A. (2008). Resistencia juvenil como manifestación de la política no tradicional. Revista Nómadas, (29), 173-184.

Di Tomaso, R., Farías, C. y Fidel, C. (2008). Territorio, condiciones de vida y exclusión. El partido de Quilmes. Buenos Aires: Ed. CLACSO-CROP.

Echeverri, J A. (2004). Territorio como cuerpo y territorio como naturaleza: ¿diálogo intercultural? En Surrales, A., y Garcia Hierro, P. (ed.). Tierra adentro. Territorio indígena y percepción del entorno (pp.259-276). Lima: Tarea Grafica Educativa.

Escobar, A. (2003). El lugar de la naturaleza y la naturaleza del lugar: ¿globalización o postdesarrollo? En Lander, E. (Comp.). La colonialidad del saber: eurocentrismo y Ciencias Sociales. Buenos Aires: CLACSO. 
Falcón, R. (1996). La resistencia obrera a la dictadura militar (una reescritura de un texto contemporáneo a los acontecimientos). En Quiroga, H. y Tcach, C. (Comp.). A veinte años del golpe. Con memoria democrática. Rosario: Homo Sapiens.

Fara, L. (1989). Luchas reivindicativas urbanas en un contexto autoritario. Los asentamientos de San Francisco Solano. En Jelin, E. (Comp.). Los nuevos movimientos sociales. Buenos Aires: CEAL.

Foucault, M. (1984). Of Other Spaces, Heterotopias. Architecture, Mouvement, Continuité, pp.46-49. Disponible en: http://web.mit.edu/allanmc/www/foucault1.pdf

Gresores, G. (2002). Conflictos obreros en la industria frigorífica bajo la dictadura militar: la huelga larga del Swift de Berisso. Ciclos, 1 (22), pp.87-108.

Kropff, L. (2004). 'Mapurbe’: jóvenes mapuche urbanos. KAIRÓS, Revista de Temas Sociales. Universidad Nacional de San Luis. Año $8-\mathrm{N}^{\circ} 14$ (Octubre /2004). pp. 1-12.

Kropff, L. (2005). Activismo mapuche en Argentina: trayectoria histórica y nuevas propuestas. En Pablo Dávalos (Comp.). Pueblos indígenas, estado y democracia. Buenos Aires: CLACSO.

Kropff, L. (2011). Los jóvenes mapuche en Argentina: entre el circuito punk y las recuperaciones de tierras. Alteridades. Vol.21. N 42. México. pp. 32-46.

Levine, D. H. y Mainwaring, S. (2001). Religión y protesta popular en América Latina: experiencias contrastantes. En Eckstein, S. (ed.). Poder y protesta popular. Movimientos sociales latinoamericanos. México: Siglo XXI.

Lefebvre, H. (2013). La producción del espacio. S.L. Recuperado en http://blogs.fad.unam.mx/asignatura/nadia_osornio/wpcontent/uploads/2 014/05/lefebvre-la-produccion-del-espacio.pdf

Magne, M. (2004). Dios está con los pobres. Buenos Aires: Ed. Imago Mundi.

Pérez, M. (2011). Retos para la investigación de los jóvenes indígenas. Revista Alteridades, (42), Jul. - Dic.

Pozzi, P. (1988). Oposición obrera a la dictadura. Buenos Aires: Ed. Contrapunto.

Rinesi, E. (1993). Seducidos y abandonados. Carisma y traición en la “transición democrática” argentina. Buenos Aires: Ed. Manuel Suárez.

Sidicaro, R. y Tenti Fanfani, E. (1998). La Argentina de los jóvenes. Entre la indiferencia y la indignación. Buenos Aires: UNICEF/LOSADA. 
Soja, E. (2011). Seeking spatial justice, Globalization and Community Series. Press, 37 (111), pp.173-177.

Toer, M. (1988a). El movimiento estudiantil de Perón a Alfonsín/1. Buenos Aires: CEAL.

Toer, M. (1988b). El movimiento estudiantil de Perón a Alfonsín/2. Buenos Aires: CEAL.

Vázquez, M. y Vommaro, P. (2009). Sentidos y prácticas de la política entre la juventud organizada de los barrios populares en la Argentina reciente. Cuadernos del CENDES 26 (70), enero-abril. Universidad Central de Venezuela. pp. 47-68

Vommaro, P. (2006). Acerca de una experiencia de organización social: las tomas de tierras y los asentamientos de 1981 en Solano. Revista de Historia Bonaerense. 13 (31).

Vommaro, P. (2010). Política, territorio y comunidad: las organizaciones sociales urbanas en la zona sur del Gran Buenos Aires (1970-2000). (Tesis de doctorado). Facultad de Ciencias Sociales de la Universidad de Buenos Aires, Buenos Aires.

Vommaro, P. (2013). Balance crítico y perspectivas acerca de los estudios sobre juventudes y participación política en la Argentina (1960-2012). Sudamérica Revista de Ciencias Sociales, (2), pp. 91-130.

Vommaro, P. (2015). Juventudes y políticas en la Argentina y en América Latina. Tendencias, conflictos y desafíos. Buenos Aires: Grupo Editor Universitario.

Williams, R. (1980). Marxismo y literatura. Barcelona: Península

Zibechi, R. (2003). Genealogía de la Revuelta. Argentina: sociedad en movimiento. Montevideo: Ed. Nordan.

Recepción de artículo: diciembre 2016

Fecha de aceptación: septiembre 2017 